\title{
Breaking Boundaries: Quality E-Learning for the Global Knowledge Society
}

\author{
doi:10.3991/ijet.v4i1.664 \\ Lalita Rajasingham $\mathrm{PhD}$ \\ Victoria University of Wellington/School of Information Management, Wellington, New Zealand
}

\begin{abstract}
The ideas and issues raised in this paper reflect a global challenge to understand the nature of E-learning in a knowledge society so that appropriate quality frameworks can be developed for new educational environments. Elearning, online learning, virtual classes and mobile learning (m-learning) evolved from distance education, and struggle to gain recognition and accreditation in mainstream education as legitimate quality higher education providers. The increasing use of information technology advances, particularly the internet present new educational paradigms and models that challenge conventional assumptions and indicators of quality assurance. Technologies are tools and in themselves are independent of quality. It is the selection, effective and appropriate use of technology in education that can improve pedagogy in diverse cultural, knowledge and delivery paradigms. What is needed is the development of global standards and quality assurance frameworks to evaluate the changing educational paradigm. This article seeks to explore the critical questions of how quality is defined, who sets whose standards, who will teach what to whom, and with what effect in times of competing paradigms in the parallel worlds of reality and virtual reality.
\end{abstract}

Index Terms-Globalisation, JITAITS, Sloan-C The Five Pillars, Teaching/Learning, Virtual Universities.

\section{INTRODUCTION}

"Henceforth, it is the map that ............Precedes the territory..."(Baudrillard, 1983, p.2)

This paper argues the need for new quality frameworks for E-Learning, as advances in information and communications technologies, particularly the internet present new paradigms and models that challenge conventional assumptions, indicators of quality assurance and accreditation. What is needed is the development of global standards and quality assurance frameworks that can improve pedagogy in diverse cultural, knowledge and delivery platforms in the parallel worlds of reality and virtual reality.

Information and communications technologies (ICTs) provide global networks for organising the world that link artefacts and people into both social and technological systems. As universities shift from mainly national classroom and transport-based learning places to information and communication technologies-based disaggregated global learning spaces, new approaches are "leading us to a very different concept of quality assurance than we've traditionally had..." (Pond, 2002, p. 186).

Thomas Kuhn (1962) defined paradigm as 'what the members of a scientific community, and they alone, share'
(Kuhn, 1977, p. 294) can be applied to any university discipline and in fact to any socially established system or framework of knowledge. Kuhn's idea that 'when paradigms change, the world itself changes with them' (1962, p. 110) reflects Foucault's view of an episteme as a worldview that is so comprehensive it is not possible for people in one episteme to comprehend the way people in another episteme think (Foucault, 1970).

\section{A. Analysis of the problem}

Distance education takes place where teacher and learner are not co-located and depends on information and communications technologies to bridge the gap between the two components. First generation distance education in the early $20^{\text {th }}$ Century was based on the technologies of print, radio and television. In the 1950sstandalone computers supplemented traditional technologies for education. Since the 1980s rapid advances in computing and telecommunications provided the internet, multimedia, the World Wide Web, and virtual reality, and research into the potential of these new technologies and applications for education began to proliferate and still continues. Digitalisation, increases in computer power, wearable computing, broadband capacity, wireless technology, nanotechnology and artificial intelligence (AI) are breaking the boundaries of conventional education systems radically changing the domain.

E-learning and its neologisms, mobile e-learning, online learning and virtual classes evolved from distance education, and struggle to gain recognition in mainstream education as legitimate quality higher education providers. As the 'new kid on the block', new delivery systems test conventional assumptions as to the quality of content and delivery approaches. The American Federation of Teachers (AFT) cited in Carol Twigg's (2001) Pew Symposium, Online Learning: Moving Beyond No Significant Difference, believes that teaching and learning are inherently social processes and consider 'same-time same-place' interaction central to a successful educational experience May, 2000, http://www.aft.org/pubs-reports/ higher_ed/distance.pdf

University systems are designed for the prevailing paradigm, episteme and infrastructures in the society in which they operate. While the medieval university paradigm was based on theology, the industrial university paradigm is based on transport and building technologies that brings together teachers and learners in classrooms as communications systems where teachers help learners to apply knowledge to problems. (Tiffin \& Rajasingham, 1995). However, in today's distributed internet-based global learning environments, education is becoming 
competitive, commercial and big business that demand new quality assurance frameworks.

As mobile access devices such as wireless laptops, WiFi, mobile phones, PDAs for learners that are 'digital natives' m-learning is a natural extension to e-learning, and is becoming the preferred mode of learning especially in the developing world, for example India where landline telephony is still underdeveloped, the rapid growth in mobile phones provide anytime, anywhere learning. Mlearning is in its infancy and a discussion on its effectiveness in learning is beyond the scope of this paper. It is noted, however, that a number of projects are now examining the potential of emerging new technologies for e-learning, and mobile working www.wearitatwork.com

According to Ann Duin, in the emerging learning market space, universities will offer a smorgasbord of courses and degrees. (Duin et al, 2001). But what is quality and, who sets whose standards? Carol Twigg (2001) provides a useful platform where she examines this question from a degree-granting institutional perspective. She and Bob Heterick argue that technology enables us to disaggregate the place, the content, the delivery, and judgments, and so unbundles the instructional process. By separating instruction from assessment, teaching from degree-granting, content development from content delivery, and service from compliance, traditional roles are redefined and new ones emerge. (Twigg, 2001).

John Tiffin describes the attempts to use educational television (ETV) and the use of pictures as a panacea for educational problems in the literacy and numeracy-based education systems of the 1970s, and concluded that ETV never worked as promised. Television had the potential to bring learners images of the real world in a way that classrooms could not match, but the examinations that were used to measure the quality of education never recognised this. What was examined was what students knew that was in words and numbers, not what they could see in the world around them. So when researchers contrasted teaching by television to teaching in class they tested verbal and numerate knowledge and found, not surprisingly, that there was no significant difference. (Tiffin, 2006).

It is argued that in contrasting e-learning in multimediated environments with conventional classroom learning, the 'no difference' phenomena will prevail unless change is made in the way we examine education to measure the indicators that are relevant to e-learning, online learning and virtual learning.

While we learn through our five senses, historically, education has privileged alphanumerics. Internet technology systems are shifting from sound and visual intensive systems that are the same for everyone, to a form of wearable head mounted unit that addresses the individual eye and ear making it possible for e-learning to be conducted in HyperReality and other emerging technological platforms that provide fully immersive environments where teachers and learners come together as telepresences no matter where they actually live. (Tiffin \& Rajasingham, 2001).

Whatever can be done when teachers and students come together in a conventional bricks and mortar classroom can be done in a virtual class based on the merger of computers and telecommunications, but where conventional classrooms are only available to teachers and students who live in the area around it that is made available by local transport systems, virtual classes are available to anyone, anywhere making the globalisation of education possible.

So what difference does it make to the quality of education whether teachers and students come together from the local neighbourhood or come together from anywhere in the world?

\section{B. Problems of definition}

The ideas and issues raised in this paper reflect a global struggle to understand the nature of tertiary education in a knowledge society so that appropriate quality frameworks can be developed to evaluate new educational environments. We live in a time of competing paradigms and parallel worlds of reality and virtual reality, and this is reflected in competing metaphors. Denis Gooler (1986) saw networked learning as a public utility. Parker Rossman (1992) wrote of an emerging worldwide electronic university. Tiffin and Rajasingham (2003) seek a global virtual university. Terms such as cyberuni, cyberlearning, e-university, virtual class, and virtual university, e-learning and mobile (m-learning) are proliferating. In this environment quality assurance becomes a moving target (Twigg, 2001).

John Daniel (2006) defines quality as: 'fitness for purpose at minimum cost to society' with the emphasis on 'purpose'. However, the greatest challenge remains the definition of quality with reference to education. Like knowledge, quality assurance is an abstract, referential, and paradigmatic concept. Nancy Parker (2004) suggests that 'quality is burdened with the legacy of failed management fads, and the pressure to apply management techniques to higher education come from a perceived crisis in confidence with post-secondary systems, and the growth of state-sponsored accountability systems (Parker, 2004). Citing Wildrick (2002: 130) who suggests that if organisations want to improve something, it must first be measured. Systems designed to guarantee that manufacturing processes would meet technical specification may not be possible or even desirable in the dynamic and heterogeneous environment of higher education (Wildrick et. al., 2002).

Quality assurance systems were designed for the national university of the industrial age with intimations of Frederick Taylor's time/motion studies and micromanagement. Today, these systems are implemented at national level by bureaucratic hierarchies that encourage management and administrative creep in universities that have little to do with improving pedagogy, creativity and innovation, but rather the pursuit of the business model for profitable financial imperatives.

Other quality variables that are complex and difficult to measure in education include course curricula content, pedagogy and learning outcomes. The concept of 'quality' applied in higher education is abstract, subjective, relative and complex. Who defines quality? In what context? For whose teaching and learning environments? How is knowledge assessed and accredited? How is quality measured and managed? These are some of the challenging questions that face E-Learning.

Tiffin and Rajasingham (1995) take a neo-Vygotskyan (1978) perspective and argue that education is interactive communications when teacher helps learner to apply 
knowledge to problems (1995; 2003). In the emerging knowledge economy, to quote Harold Lasswell's Communication dictum, the question is who will teach what to whom in what channel, with what effect?

Accountability for quality is not a new phenomenon for universities. Modern national universities as we know them are state subsidised and taxation funded, and have endeavoured to respond to the quality control movement of the last decade that now demand changes in the way quality frameworks for higher education are designed, measured and accredited.

Universities today are called upon to demonstrate the quality of their services to stakeholders that include students as paying customers, faculty, employers and government agencies. Standards are of critical importance, and universities have mechanisms in place in which the triple helix of strongly focused research, learning and teaching, and knowledge dissemination are tightly interrelated, each shaping and strengthening the other by regular reviews of programmes to improve quality and learning outcomes. These take the form of internal programmes reviews and benchmarking against national and external standards in the quality of curricula, teaching and learning outcomes. In addition, most countries have national quality assurance authorities, for example, the Australian University Quality Assurance (AUQA), the Quality Assurance Agency for Higher Education (QAA) in Britain, and the New Zealand Qualifications Authority (NZQA).

Furthermore, some critical initiatives and projects are now being developed to examine issues related to quality in e-learning. http://www.enqa.eu. The Baldridge National Quality Program usefully outlines the criteria for performance excellence for institutions in the USA and relates to the following aspects: leadership; strategic planning; student, stakeholder and market focus; measurement, analysis, and knowledge management; workforce focus; process management; and results, such as student learning objectives http://www.quality.nist.gov/ Education Criteria.htm. The European Foundation for Quality in E-learning takes a federative approach: http://www.qualityfoundation.org

Quality assurance is taking on new meanings as universities expand their teaching environments on the internet and online, mobile learning and virtual classes grow rapidly to cater for the increasing demand worldwide for higher education which provides the engine for economic growth and cultural integrity. However, despite the abundance of research on quality management, there are other universal variables that defy measurement of quality in education such as knowledge content and pedagogy. In the emerging knowledge economy, to adapt Harold Lasswell's Communication dictum, the question is who will teach what to whom in what channel, with what effect? Quality is related to the effectiveness and appropriate for the learning process and approaches. Do we have a breakthrough technology to measure quality in education such as surgery got with anaesthetics and doctors with antibiotics? (Tiffin, 2006).

Over the last 150 years with the rise of the industrial society, nation states have taken control of education. The whole pyramidal paraphernalia of national education systems has been dedicated to preparing people to be good citizens. They learn to read and write in the national language, to trade in a national currency, to sing the national songs, to take pride in the national history, geography, art and literature and to accept the national law and pay taxes. Who was allowed to teach, what constituted the curriculum and the process whereby degrees and certificates were awarded became something that was defined by state legislature. Education became a public good, a citizen's right and a compulsory rite of passage.

All this began to change in the 1990s with the coming of the internet, and like television and trade, learning has been freed from national boundaries. It has become global and part of the rite of passage for the global mobile citizen. It is becoming possible for anyone anywhere to get an education on the internet, provided of course that they can pay. Global education on the internet is not supported through taxes and when the user pays and the market is global, how then do we determine quality in education?

The World Trade Organisation seeks to make education an information service that can be traded worldwide, but there is a problem with this. Quality in education is defined by nations and there are many nations and many definitions of quality education. However, the developed countries, especially those that speak English, assert their national standards as global standards. The rapidly growing global trade in teaching is based on their national curricula, their qualifying and accreditation systems and subsidised by their governments. It is suggested a framework be developed to establish educational quality at a global as well as at a local level. Otherwise globalisation in education will, like globalisation in agriculture, be tipped in favour of the developed countries and lead to trade wars and Doha-like stalemate.

To respond to the needs of the fast changing and unpredictable future, this article adapts the Sloan-C Quality Framework and the Five Pillars to examine potential of emerging e-learning platforms such as HyperReality, Croquet and so on to reframe future developments that help to improve quality in online curricula, teaching and learning.

The quality framework is a tool for continuously improving online programmes in higher education. The Sloan Consortium (Sloan-C) coined the term 'asynchronous learning networks (ALN)' in 1993 as people-networks for anytime, anywhere learning (Moore, 2003). The five principles, which broadly resonate with the Baldridge National Quality Program, called the pillars of quality guide the process of continuously improving outcomes. In 1997, Frank Mayadas, President of Sloan-C, argued that any learner who engages in online education should have, at a minimum, an education that represents the quality of the provider's overall institutional quality. Any institution, he maintained, demonstrates its quality in five inter-related areas - learning effectiveness, access, cost-effectiveness and institutional commitment, faculty satisfaction, and student satisfaction. These five have become Sloan-C's Five Pillars of Quality Online Education, the building blocks which provide the support for successful online learning. The Sloan-C inter-related Pillars are summarised:

The Learning Effectiveness pillar is concerned with ensuring that online students are provided with a high quality education that should at least be equivalent to that 
of traditional students. Not necessarily to duplicate the learning experiences in traditional classrooms, instructors and course developers should take advantage of the unique characteristics of online environments to provide learning experiences that represent the distinctive quality of the institution offering them. Effective practices that support learning effectiveness include: course design, learning resources, faculty development, learner characteristics, pedagogy, interaction, assessment, and learning outcomes that reflect student satisfaction, retention, achievement and performance.

Cost-effectiveness and institutional commitment to quality and finite resources require continuous improvement policies for developing and assessing costeffectiveness measures and practices. The goal is to control costs so that tuition is affordable yet sufficient to meet development and maintenance costs, and to provide a return on investment in startup and infrastructure. Practices for scale help to leverage key educational resources while offering new online learning opportunities to students and faculty in these categories: Institutional infrastructure, technical infrastructure, methodologies for example, conserving costs, resources, time, effort, partnerships, scalability, marketing, local and global perspectives.

Access: This pillar provides the means for all qualified, motivated students to complete courses, degrees, or programmes in their disciplines of choice. The goal is to provide meaningful and effective access throughout the entire student's life cycle. Technical infrastructure, academic administrative services for example registration, student loans, fees and so on, student support services that include 24/7 help, readiness assessment, support social groups, and fostering learning communities, learning resources, for example library, tutoring, and DLOs (digital learning objects) course design, programme access basic information, variety of offerings, course previews, course schedules and timetable.

Faculty satisfaction is where instructors find the online teaching experience personally rewarding and professionally beneficial. Personal factors contributing to faculty satisfaction with the online experience include opportunities to extend interactive learning communities to new populations of students and to conduct and publish research related to online teaching and learning. Institutional factors related to faculty satisfaction include three categories: support, rewards, and institutional study/research provision. Faculty satisfaction is enhanced when the institution supports faculty members with a robust and well-maintained technical infrastructure, training in online instructional skills, and ongoing technical and administrative assistance. Faculty members also expect to be included in the governance and quality assurance of online programmes, especially as these relate to curricula decisions and development of policies of particular importance to the online environment such as intellectual property, copyright, plagiarism, royalties, collaborative design and delivery. Faculty satisfaction is closely related to an institutional reward system that recognises the rigor and value of online teaching. Satisfaction increases when workload assignments/assessments reflect the greater time commitment in developing and teaching online courses, and equitable address of institutional rewards, promotion issues, administrative and technology support.
Students Satisfaction reflects the effectiveness of all aspects of the educational experience. The goal is that all students who complete a course express satisfaction with course rigor and fairness, with professor and peer interaction, and with support services. Online students put a primary value on appropriate, constructive, and substantive interaction with faculty and other students. Effective professors help students achieve learning outcomes that match course and learner objectives by using current information and communications technologies to support active, individualised, engaged, and constructive learning. As consumers, students are satisfied when provider services-learning resources, academic and administrative services, technology and infrastructure support - are responsive, timely, and personalised.

The pillars are inter-related, and conventional universities have a long and successful history of established procedures and structures for the interaction between the pillars. However the rapid advances in the Internet, multimedia and m-learning will impact on the interrelation between Sloan-C's five pillars, changing how teaching, learning, knowledge creation and disseminationthe universals of universities-will be conducted in the future. It is suggested that future higher education will be global and commercial, and will be on broadband using virtual reality (VR) HyperReality (HR) Croquet, SecondLife, and artificial intelligence (AI) providing learning through our five senses.

\section{The Teaching/Learning/Knowledge Nexus}

There are some critical factors that constitute higher education, the core functions of a university that will not change whatever the episteme, the place, the language, the culture or the media used (Tiffin and Rajasingham, 2003). The main difference that distinguishes e-learning from oncampus learning is that instead of bringing students and teachers together physically by means of local transport systems and buildings for face-to-face interaction, which is becoming increasingly costly and unaffordable, elearning uses computers and telecommunications to bring them together as telepresences on the global internet where the professional application of knowledge increasingly takes place in a global as well as in local contexts.

The universals of a university are the creation, processing, dissemination and application of knowledge adding value that provides the engine that drives economic growth. But knowledge is an elusive concept being deconstructed into a multiplicity of subjects, but is seen differently from university to university, country to country and language to language. The growing fragmentation of knowledge and lack of consensus as to what constitutes knowledge creates a context for discordant value judgement of quality. From a postmodern perspective, we see multiple 'knowledges' on the same theme (Lyotard, 1984) and all seek legitimisation for problem solving in their own cultural settings. As the university changes with a new episteme, so too must the knowledge it teaches and researches.

Professionals need to know about international practice as it operates in the global economy. Increasing socioeconomic inequalities, bloody conflicts, terrorism, pandemics and environmental issues know no frontiers, and people everywhere need to be able to collaborate 
internationally to deal with these global issues and come up with quality decisions. From being teacher controlled, education is becoming learner-centred, non-linear, and self-directed. Teachers move from centre stage of the education process to become facilitators of learning, shifting paradigms.

Furthermore, universities face competition and commercialisation as students now compare and evaluate what is taught in other countries by using the World Wide Web, and linking in chat rooms, blogs, wikis, Bebo, SecondLife and so on with students from around the world. Universities need to attract students, remove the regulatory and administrative barriers to developing innovative quality curricula that seamlessly map onto the students' preferred technology platforms. Let the customer decide what they want, and provide it. Let good teachers and good researchers be well remunerated and supported, and let go the ineffective researchers and teachers.

\section{Improving quality in curricula design}

Curricula design for the global market is needed to allow societies to act global, and then localise in consonance with local thinking, to ensure John Daniel's words, 'fitness of purpose at minimal cost to society'. With instructional design principles for internet based learning, basic courses that are the currency of higher education whatever the country can be re-addressed from the multiple perspectives of different countries, cultures and languages to develop new curricula to match global concerns (Tiffin and Rajasingham, 2003).

As education becomes big business, universities are challenged to resolve the dichotomy between business ideals and pedagogical imperatives that embody the universals of a university that will help improve the quality of what and how we teach in culturally appropriate ways in a globalising world. As universities become businesses for profit, with reduced government subsidies and staffing, increasing on-seat student numbers and cutting staff and student support systems, staff/student ratios rise, and inevitably standards fall.

Traditionally, it was the teacher who decided what goes into curriculum and how it will be assessed by setting and grading exams and summatively measures if learning has taken place. This process has inherent flaws as we still grapple with the concept of measurement of learning, and there are yet no global standards by which to evaluate a degree, a diploma or a course credit. There is no way of knowing if a degree from say Peking is better or worse than one from Harvard, Heidelberg, Cambridge or Madras .Many countries have some kind of ranking for institutions of higher education that indicate a pecking order of prestige and there are global listings that rank universities to attract students, but they do so on the basis of research, rather than on effective teaching and learning outcomes. In a situation where there are no global standards, universities are challenged to compete in the new business world while maintaining their universals.

To ensure quality and accreditation, e-learning in higher education will need to adopt a rigor in course design and assessment, and introduce new processes and strategies beyond that which now operate in conventional institutions. This includes separating summative assessment from teaching, and developing curricula in conjunction with national and international associations in the subject field, and so set the new global standards (Tiffin, 2004).There is already some precedence for a global qualifying system in the International Baccalaureate (IB). The programmes lead to the International Baccalaureate exam and a qualification that is recognised by the world's leading universities and sets global standards in school education.

The main difference between a global virtual university and any of its predecessors is in the technology of the communication system by which teaching and research is done. Education is a subset of communications, and all previous university paradigms have been based on face-toface communication supported by some form of reading, writing and display technology, for example a whiteboard, and modelled themselves on the world for which they were preparing their students. The virtual university/ elearning/m-learning will prepare people for an entirely different world and they use computers and telecommunications to bring teachers, students, knowledge and problems together in a virtual learning space.

Global education deals with such subjects as mathematics, science and medicine, and national education with subjects such as history, literature and law as learners apply global knowledge and concepts in their own local contexts. When more knowledge is gained through culturally diverse interaction, more worldviews are being asserted giving rise to increasing cultural, political and ideological conflict as value, power and cultural claims are asserted.

To respond to multiperspectives in a globalised world, the virtual university/e-learning will need to be global, commercial, multilingual and multicultural on the internet where students are equipped with global skills to solve global problems, and at the same time act local in consonance with their own cultures and social networks (Rajasingham, 2003).

The technology that does this will also make it possible for e-learning to be conducted in HyperReality that allows teachers and students to come together as telepresences no matter where they actually live. Distributed virtual realities that make this possible have been available on the internet for over a decade. ActiveWorlds, SecondLife and other similar fully immersive worlds are now home to hundreds of experiments in education and gaming in virtual reality. HyperReality is a more advanced technology developed in Japan by Nobuyoshi Terashima at Waseda University that seeks to make the interaction between the physically real world and virtual worlds and between human intelligence and artificial intelligence more intuitive and seamless.

\section{E. The HyperClass}

As new clusters of technologies like nanotechnology, artificial intelligence (AI) and HyperReality (HR) become available, they provide revolutionary infrastructures where education through our five senses will be available to anyone, anywhere at anytime in culturally appropriate ways, replicating the communications functions of a faceto- face classroom, not to replace it but toprovide complementary loci for learning.

A HyperClass is the interactive conjunction of a real class made of atoms with a virtual class made of bits of information. It makes possible a future where the people 
and the objects around you may be real or may be virtual and may have human intelligence or artificial intelligence providing multimediated, immersive simulated learning environments. It is argued that because HyperClasses in universities can exist in real and virtual dimensions at the same time, they will provide an intersection between the local and global dimensions in education.

A student could go to a conventional class in a conventional university or stay at home and use a PC and the internet to link to a virtual class in a virtual university. A HyperClass allows a student to do both. A HyperClass exists where the virtual and real dimensions intersect. This is a coaction field where students and teachers in a conventional classroom can synchronously interact with students and teachers in other universities that may be in different locations.

A coaction field conceptualised by Terashima (2001, pp. 9-12) is where students and teachers in a conventional classroom can synchronously interact for the purpose of learning with students and teachers in other universities, possibly in other countries. The HyperClass is where real and virtual dimensions of students and teachers intersect providing a common field to reconcile the learning that is local with learning that is global in order to understand the subject from multiple perspectives of other cultures than one’s own (Tiffin and Rajasingham, 2001; 2003).

Participants in a HyperClass come together because of their interests in a specific subject on a shared domain of knowledge. In the HyperClass, the relationship between knowledge and problem domains suggests another important contrast to conventional classroom processes. In a conventional classroom the application of knowledge to problems is expressed symbolically, through alphanumeric notation and two-dimensional still pictures displayed on a display unit such as a whiteboard.

However, Tiffin and Rajasingham (2001) suggest that when problems have a real life referent in the participants' social reality, then classrooms with whiteboards may not be the best place for learning and proves the inadequacy of alphanumeric and diagrammatic instruction alone. The challenge is to transfer learning from the classrooms to real life situations and testing the application of knowledge to real life situations in whatever form they take, in multimediated simulated environments. The HyperClass introduces a new dimension in education with the juxtaposition of knowledge with problems that have a referent in physical reality. The world's first successful HyperClass experiment took place in December 2000 with participants from New Zealand, Australia and Japan. Each participant appeared as an avatar to each other, and involved learning how to place a virtual computer disk into a virtual computer that was located in Japan. This was followed by the collaborative study of Japanese artefacts, where each participant located in their own country and environment took part seamlessly as telepresences with participants across three countries via the internet and computer display unit. As with many projects, further research is hampered by the tight fiscal university environment.

Basically, with HyperReality technology, reusable objects are created in 3-D using an array of videocameras, creating a database/library of problem case studies or learning objects that could include dangerous conditions. Learners could for example, be faced with a vast array of different situations and could seek solutions to their problems with the help of their teachers and peers from diverse cultural perspectives where each participant or group can manipulate the 3-D modelled learning objects (Terashima, 2001). A significant strength of HyperReality as contrasted with virtual reality today is for example, that the communication process in virtual reality is prescribed using the shapes and designs that have already been created as computer generated virtual reality by computer graphic designers. HyperReality on the other hand allows a syncretion of cultures, where the quality of the content being studied can be designed, altered, and objects modelled by the participants to catalyse collaborative learning and problem solving from multicultural perspectives. It is suggested that this capability is critical for improving the quality of the knowledge content being studied in culturally appropriate ways. A number of software developments for fully immersive environments such as Croquet an open source application that allows multi device collaborations being developed in the USA for education http://www.opencroquet.org/index.php/ About the Technology

An increasing number of applications that relate to the gaming industry are becoming available and is now big business. Further research is needed to examine their potential for education.

\section{F. Improving quality in pedagogy-JITAITS}

Perhaps the most profound aspect of the teacher/learner axis in a HyperClass is that the avatars of teachers and students may not necessarily represent human intelligence. We are familiar with the little cartoon character, a wizard looking like a paper clip that keeps popping up on the computer screen offering to help where someone has tried to programme a just-in-time (JITAIT) artificially intelligent teacher. While the wizard today is still to provide meaningful responses, the technology is improving and is becoming more intuitive. In a HyperClass a teacher and a learner can be virtual or real. A virtual teacher can have human intelligence (HI) or artificial intelligence (AI). Teachers and learners can communicate synchronously, using speaking avatars, or asynchronously, using written words or visuals. Knowledge and problems can be embodied in the teacher and the learner or they can be represented alphanumerically or in simulacra. Problems can be real, but knowledge is always abstract.

Today human teachers can only respond immediately to a learner in working hours and if there is only one student seeking help. In large classes student questions have to wait until a teacher is available. In higher education much learning is done asynchronously and students get feedback on an assignment a week or more after doing it and most students have forgotten the things they found difficult. It is time for the JITAIT. As the name implies, this is an AI teacher that can be available whenever and wherever a student needs help (Tiffin and Rajasingham, 2003).

JITAITs are expert systems, effective where the domain of knowledge they address is restricted, paradigmatic and orientated toward problem solving. A JITAIT can, therefore, be an expert teacher on a subject, for example, pathology that formed the domain of medical knowledge of a coaction field in HyperReality. JITAITs would always be ready to help any learner in the coaction field and would improve from each encounter with a learner, 
provided it received feedback from a human teacher and could act as personal teachers to individual students. JITAITs could have avatar form and a personality and act as a guide and mentor in the manner of the servant-tutor pedagogues of ancient Greece. As each intake of students asks the same questions and has the same problems JITAITs can be used, and at this level could be shared between human and AI tutors. As time went by and JITAITs handled more and more FAQs, their role would increase and the student teacher ratio could be progressively increased without lowering quality.

The upper level is that of the subject specialist, the professors and professionals who have achieved academic stature through research, publications and experience and can arbitrate on content. Their primary purpose is to communicate a synthesis of the subject matter in a way that brings it up to date, places it in context and encourages students to question. They do this by lecturing, and supported by a team of teaching assistants who do the tutoring, leaving the professor to lecture to very large classes and manage the media event. With e-learning they could stream their lectures to the whole world, and there need be no limits to the numbers who could attend. Instead of being salaried employees, professors who could attract such numbers would be valuable property and they could relate to their universities in the way authors relate to their publishers (Kats, 1999, p. 48) receiving royalties for each student taking their programme.

\section{G. Access, Quality and Costs}

John Daniel (2004) argues that open and distance learning allows education to break out of the iron triangle that has constrained its impact throughout history which he describes as the vectors of access, quality and cost, (quantity, quality and equity) where the assumption by educators and the public is that education is a zero-sum game between these variables. On this assumption, increasing access to education will lower quality and raise overall cost. Similarly, raising quality will increase costs and therefore reduce access. Daniel challenges universities to break this iron triangle and the link between quality and exclusivity in education.

While the complex issues of cost factors associated with going online, and quality assurance must be open to critical analysis, and further research, this is beyond the scope of this article.

\section{END THOUGHTS...}

While the technology is changing and will continue to change, what will not change is the interactive communication process of higher education, where we will continue to design, explain, demonstrate, question and set problems in higher education, and to do this in a way that ensures quality, equity and sustainability.

Within the framework of the Sloan-C's Five Pillars, it is suggested that e-learning has the potential to make higher education more efficient, more cost effective, and more accessible, increase student and staff satisfaction, and improve quality. This article suggests that the HyperClass, virtual universities, e-learning and m-learning could help improve quality in what we teach, and how we teach in the knowledge society, and signal a paradigm shift in higher education. As universities become virtual, commercial and global, the mechanisms to evaluate and accredit their programmes, their teachers and their students need to be addressed anew. As ICT capabilities grow, what standards of quality are, how they are to be measured and by whom and with what effect still remain to be negotiated.

\section{REFERENCES}

[1] J. Baudrillard, Simulations, New York: Semiotext(e) 1983.

[2] J.Daniel, "Higher Education, Teacher Education, Distance education: What is Quality and Who says so?” In Workshop on Materials Development for Quality Assurance in Higher

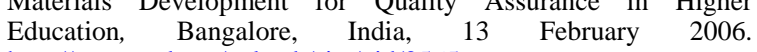
http://www.col.org/colweb/site/pid/3565

[3] ..., Mega-universities and knowledge media: technology strategies for higher education, London: Kogan Page, 1996.

[4] , "The sustainable development of open and distance learning for sustainable development”, The Commonwealth of Learning Institute

[5] , Strategies for Sustainable Open and Distance Learning, Canada, 9 June 2004, http://www.col.org/colweb/site/pid/3642

[6] M. Foucault, The Order of Things, New York: Pantheon House 1970.

[7] D. D. Gooler, The Educational Utility: The Power to Revitalize Education and Society. Englewood Cliffs, NJ: Educational Technology Publications 1986.

[8] T. S. Kuhn, The Structure of Scientific Revolutions, Chicago: University of Chicago Press 1962.

[9] ..., "Second thoughts on paradigms", in The Essential Tension: selected studies in scientific tradition and change, Chicago: University of Chicago Press 1977.

[10] J.Lyotard, The Postmodern Condition: A report on knowledge, Minneapolis: University of Minnesota Press 1984. .

[11] J. Moore, The Sloan Consortium Quality Framework and the Five Pillars, USA: Sloan Consortium 2003.

[12] N. Parker, “The Quality Dilemma in Online Education” in Theory and Practice of Online Learning., Terry Anderson \& Farthi Elloumi (Eds.) Chapter 16 Athabasca University 2004: cde.athabascau.ca/online_Book (Retrieved 12 March 2008).

[13] W. K.Pond, "Twenty-first century education and training Implications for quality assurance", in Internet and Higher Education, 2002, (4), 185-192.

[14] L. Rajasingham, “The Impact of Universities on Globalisation”, in Intercultural Communication: A Global Reader. Fred Jandt (ed.) CA: Sage Publications Inc., 2003.

[15] P.Rossman, The Emerging Worldwide Electronic University: Information Age Global Higher Education, Westport: CT: Greenwood Press 1992.

[16] N. Terashima, "The Definition of Hyper Reality”, in J. Tiffin and N. Terashima (Eds.) HyperReality: Paradigm for the Third Millennium. London and New York: Routledge 2001.

[17] J.Tiffin, \& L. Rajasingham, "HyperClass", in J. Tiffin and N. Terashima (Eds) HyperReality: Paradigm for the Third Millennium, London and New York: Routledge 2001.

[18] J.Tiffin, \& L.Rajasingham, “ Foreword”, in Duin, A. H.; Baer, L.; \& Starke-Meyerring, D. (2001). Partnering in the Learning Marketspace, EDUCAUSE Leadership Strategies, (4), April 2001, xi-xiv). San Francisco: Jossey Bass Inc. 2001.

[19] J.Tiffin, "Globalisation, Localisation and the Quality of Education", Keynote Presentation, Promoting Quality in Distance, Flexible and ICT-based Education, $22^{\text {nd }}$ World Conference, International Council for Open and Distance Education, 3-6 September (2006) Rio de Janeiro, Brazil.

[20] J. Tiffin, \& L.Rajasingham, In Search of the Virtual Class: Education in an Information Society, London, and New York: Routledge 1995.

[21] ... The Global Virtual University, London, and New York: Routledge 2003.

[22] C. Twigg, Quality Assurance for Whom? Providers and Comsumers in Today's Distributed Learning Environment, http://eric.ed.gov/ERICDocs/data/ericdocs2sql/content_storage_01 10000019b/80/1a/8a/db.pdf

[23] L. S. Vygotsky, Mind in Society: The Development of Higher Psychological Processes, Cambridge, MA: Harvard University Press 1978. 
BREAKING BOUNDARIES: QUALITY E-LEARNING FOR THE GLOBAL KNOWLEDGE SOCIETY

\section{AUTHOR}

Lalita Rajasingham is Associate Professor at the School of Information Management, Victoria University of Wellington, New Zealand.

(e-mail: lalita.rajasingham@vuw.ac.nz)

This work was supported in part by the U.S. Department of Commerce under Grant BS123456 (sponsor and financial support acknowledgment goes here).Manuscript received 23 September 2008. Published as submitted by the author(s). 